\title{
PARTIAL 18q TRISOMY AND 18p MONOSOMY RESULTING FROM A MATERNAL PERICENTRIC INVERSION, inv(18)(p11.2q21.3)
}

\author{
Takeshi Asano, ${ }^{1}$ Tatsuro Ikeuchi, ${ }^{2}$ Tamiko Shinohara, ${ }^{3}$ \\ Hisashi ENoKIdo, ${ }^{4}$ and Kiyoshi Hashimoto ${ }^{1}$ \\ 1 Department of Pediatrics, Nippon Medical School, \\ 1-1-5 Sendagi, Bunkyo-ku, Tokyo 113, Japan \\ ${ }^{2}$ Department of Cytogenetics, Medical Research Institute, Tokyo Medical and \\ Dental University, 1-5-45 Yushima, Bunkyo-ku, Tokyo 113, Japan \\ ${ }^{3}$ Department of Human Cytogenetics, Japan Red Cross Medical Center, \\ 4-1-22 Hiro-o, Shibuya-ku, Tokyo 150, Japan \\ ${ }^{4}$ Department of Pediatrics, Shimodate Municipal Hospital, \\ 1658 Tamado, Shimodate, Ibaraki 308, Japan
}

\begin{abstract}
Summary A 7-year-old boy with dysmorphic features was found to have a recombinant chromosome 18 , rec(18), resulting from meiotic recombination of a maternal pericentric inversion, inv(18) (p11.2q21.3), as defined by high-resolution banding. He was trisomic for the long arm (q21.3-qter) and monosomic for the short arm (p11.2-pter) of chromosome 18. His clinical features were compared with those in other rec(18) cases, and also those in monosomy $18 \mathrm{p}$, trisomy 18 qter and full trisomy 18 syndromes. The risk of recombinant formation for inv(18) carriers was also discussed.
\end{abstract}

Key Words chromosome 18, recombinant chromosome, partial monosomy $18 \mathrm{p}$, partial trisomy $18 \mathrm{q}$

\section{INTRODUCTION}

Clinical characterization for partial trisomy $18 \mathrm{q}$ and for partial monosomy $18 \mathrm{p}$ has been well established (de Grouchy and Turleau, 1977; Schinzel, 1984). However, combination of these chromosomal anomalies is very rare, and only 4 such cases resulting from recombination of parental pericentric inversions have been reported to date (Vianna-Morgante et al., 1976; Turleau and de Grouchy, 1977; Kukolich et al., 1978; Andrews et al., 1982). We report here another case

Received July 10, 1991; Accepted August 22, 1991.

Reprint requests to: Takeshi Asano, M.D., Department of Pediatrics, Nippon Medical School First Hospital, 3-5-5 Iidabashi, Chiyoda-ku, Tokyo 102, Japan. 
of recombinant chromosome 18 with duplication of the distal one-third of the long arm and deficiency of the terminal segment of the short arm, which arose from a maternal balanced pericentric inversion, inv(18) (p11.2q21.3). The patient's clinical manifestations and the risk of recombination for inversion carriers will be discussed in association with the chromosomal regions involved in the duplication and deficiency. A brief report on this patient has been presented preliminarily elsewhere (Shinohara et al., 1985).

\section{CASE REPORT}

The propositus, born after 39 weeks of gestation, was the second child of a 30-year-old mother and a 32-year-old father, who were both phenotypically normal. There was consanguinity in the mother's pedigree, i.e., the mother's parents were cousins. The mother had a history of two spontaneous abortions and one stillbirth. The elder sister of the propositus was phenotypically normal. The propositus was born after an uneventful pregnancy and delivery, weighing 2,890 g. At birth, however, facial pallor was noted and he was transferred to an incubator. He complained of failure to thrive, and the intake was tube feeding. At 2 weeks, the body weight was $3,070 \mathrm{~g}$, the length was $50 \mathrm{~cm}$, and the clinical manifestations were as follows: hypotonia, dolichocephaly, slight frontal bossing, a prominent occiput, asymmetrical and narrow palpebral fissures, large and low-set ears, an upturned nose, a small mouth, a high-arched palate, micrognathia, microglossia

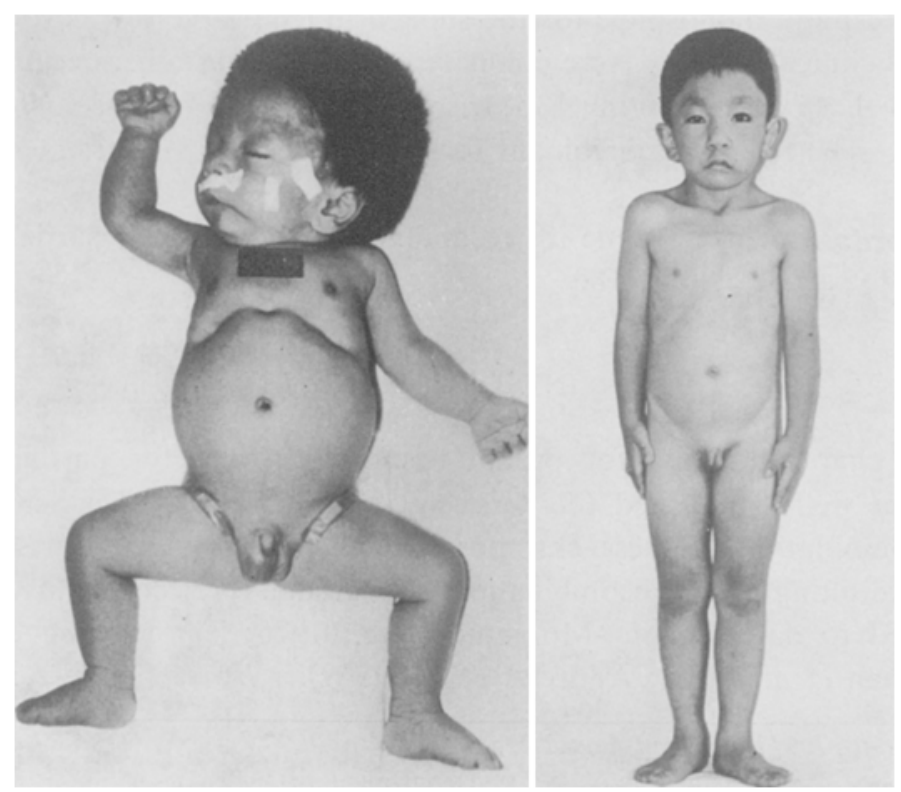

Fig. 1. Propositus at 2 weeks of age (a) and at 7 years of age (b). 
(Fig. 1a), camptodactyly of both the fifth fingers, typical overlapping of the two medial fingers by the index and fifth fingers in both hands, lack of a 12th rib on the right side, and micropenis. At age 3 months, he was able to control his head steadily and smile responsively. At 15 months of age, he was able to roll over and to sit without support, and his developmental quotient was 41. Results of routine laboratory tests, including EEG, brain CT scan, intravenous pyelography and echocardiography, were all within normal limits.

At the age of 7 years, his body weight was $14.9 \mathrm{~kg}$ (-3.4 S.D.) and his height was $100.5 \mathrm{~cm}$ ( -3.9 S.D.). Microglossia and micropenis were still present (Fig. 1b). He was able to run, use a video-tape recorder, and speak a few words other than "mama" and "papa." He could not take solid food, however, and a nasogastric tube was still required.

\section{DERMATOGLYPHIC STUDY}

The propositus had 9 ulnar loops and one radial loop. The atd angles were $53.5^{\circ}$ on the right palm and $60^{\circ}$ on the left. There was a simian crease on the left hand and a Sydney line on the right hand. The total ridge count was 92 and c triradii were absent on both palms. The dermatoglyphics of his parents were normal.

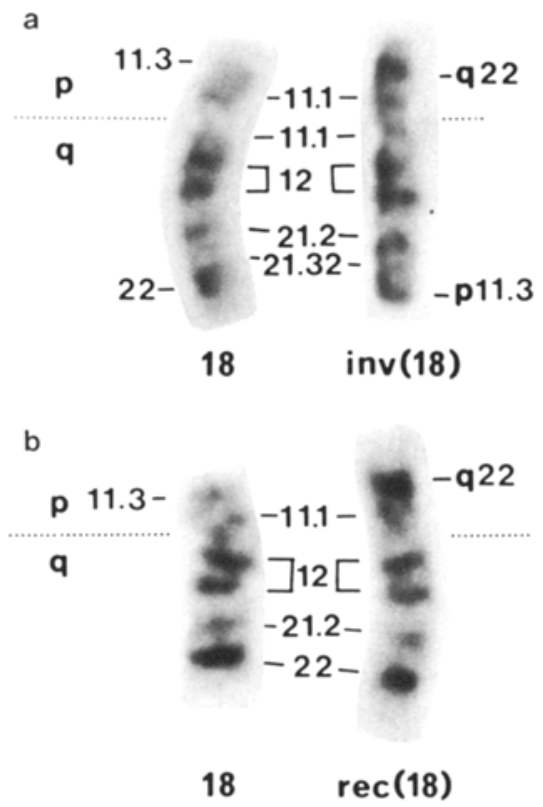

Fig. 2. Pairs of high-resolution G-banded chromosomes 18 from the mother (a) and from the propositus (b).

Vol. 36, No. 3, 1991 

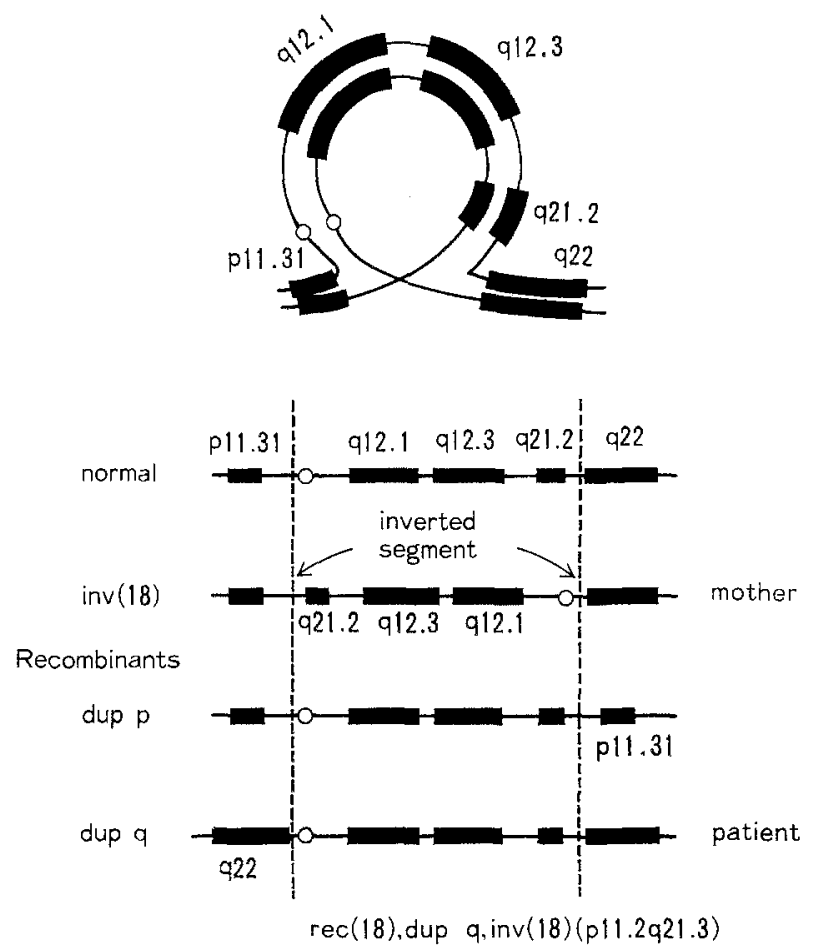

Fig. 3. Schematic diagram of meiotic pairing of the normal and inverted chromosomes 18 in the mother (upper) and formation of the recombinant chromosomes following crossing-over within the inverted segment (lower).

\section{CYTOGENETIC STUDY}

Initial karyotype analyses of the patient using cultured lymphocytes and skin fbroblasts revealed a slightly elongated short arm of chromosome 18 along with an altered band profile. Chromosome studies of lymphocyte cultures from the parents showed that the mother had a pericentric inversion on chromosome 18, whereas the father's karyotype was normal. High-resolution G-banding by the ethidium bromide pretreatment method (Ikeuchi, 1984) was performed on cultured lymphocytes from the patient and his mother. The breakpoints in an inv(18) chromosome of the mother were found to be at $18 \mathrm{p} 11.2$ and $18 \mathrm{q} 21.3$ (Fig. 2a). Thus, the mother's karyotype was identified as 46, XX,inv(18) (p11.2q21.3). A recombination event during meiosis in the mother would have given rise to the patient's recombinant chromosome 18 (Fig. 2b) if the crossing-over had occurred in the inverted segment, as shown in Fig. 3. The patient's karyotype was therefore designated 46,XY,rec(18), dup $q$, inv(18) (p11.2q21.3) mat, indicating the patient to be trisomic for the $\mathrm{q} 21.3$-qter and monosomic for the pter-p11.2 regions. 


\section{DISCUSSION}

Our patient showed a recombinant chromosome with duplication of the distal region of the long arm (18q21.3-qter) and deficiency of the short arm (18p11.2pter), which had originated from maternal balanced pericentric inversion of chromosome 18. In the literature, there have been only 7 reported cases of recombinant chromosome 18 due to parental inversions: 4 cases of long-arm duplication (associated with short-arm deficiency) (Vianna-Morgante et al., 1976; Turleau and de

Table 1. Clinical manifestations in cases of rec(18) chromosome (trisomic for q21-qter and monosomic for p11-pter), and in $18 \mathrm{p}-$, trisomy $18 \mathrm{qter}$ and full trisomy 18 syndromes.

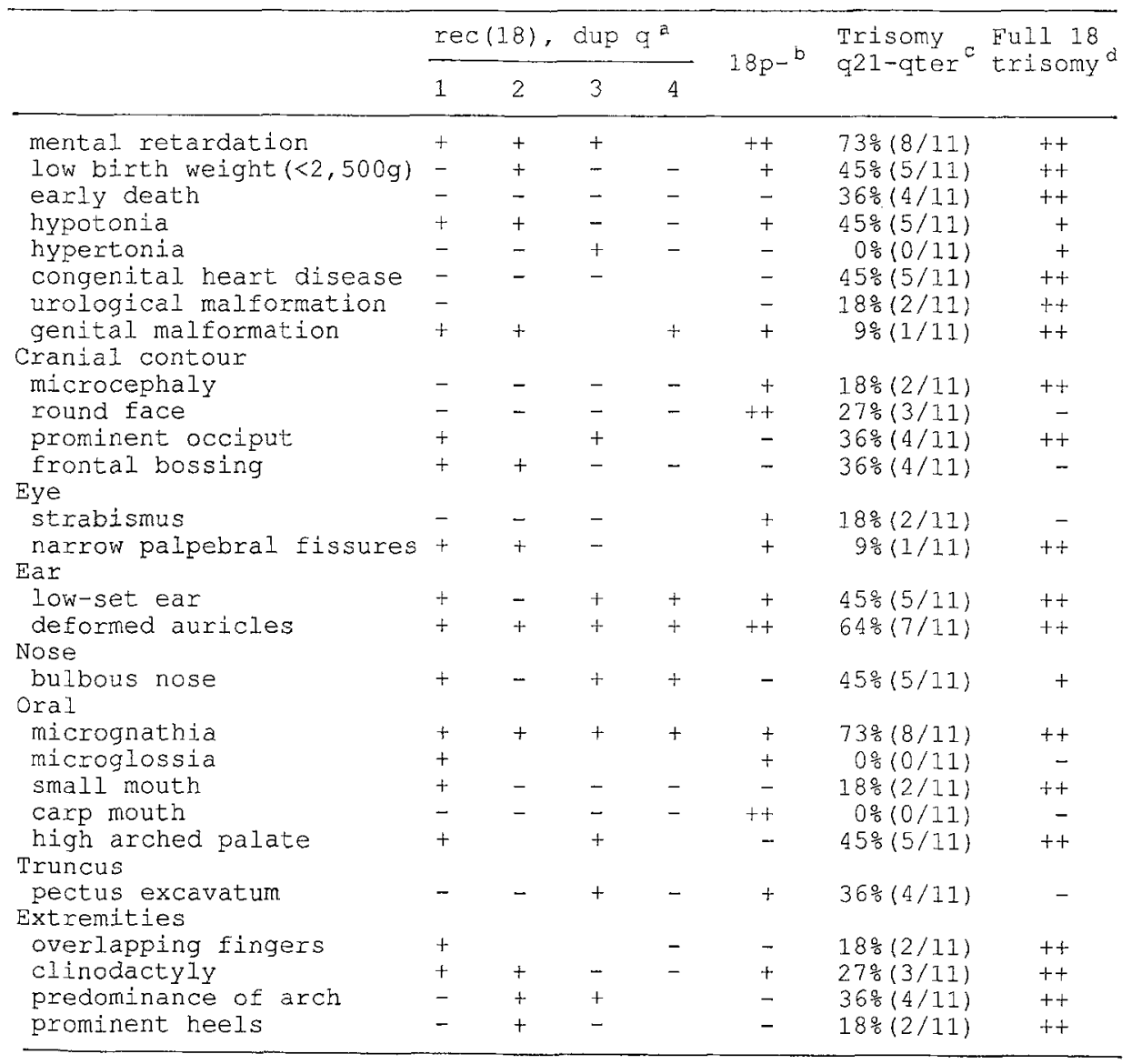

a 1, Present case; 2, Vianna-Morgante et al. (1976); 3, Kukolich et al. (1978); 4, Turleau \& de Grouchy (1977). b Based on the articles by: Kunze et al., 1972; Schinzel et al., 1974; Faust et al., 1976; de Grouchy \& Turleau, 1977; and Schinzel, 1984. c The literature cited is shown in Table 2.

d Based on articles by: de Grouchy \& Turleau, 1977; Hodes et al., 1978; Wilson et al., 1990.

Vol. 36, No. 3, 1991 
Grouchy, 1977; Kukolich et al., 1978; Andrews et al., 1982), as shown in the present case, and 3 cases of short-arm duplication (associated with long-arm deficiency) (Jacobs et al., 1974; Vianna-Morgante et al., 1976; Teyssier and Bajolle, 1980). Among the former, the case reported by Andrews et al. (1982) showed duplication of the longer segment (18q11-qter). As the duplicated and deleted segments in the other 3 cases were similar in size to those of our patient, their clinical pictures were compared as shown in Table 1.

These 4 cases are clinically similar, and share ceratin features: mental retardation, frontal bossing, deformed auricles, and micrognathia. Some minor inconsistent features seen among the 4 cases might be due in part to the slight differences in length of the unbalanced chromosome regions. The 4 patients with chromosome rec(18) showed the features seen in the 18p - syndrome (Kunze et al., 1972; Schinzel et al., 1974; Faust et al., 1976; Schinzel, 1984), but most of them are also common in the full trisomy 18 and trisomy 18 qter syndromes, as described below (Table 1). The rather unique features of $18 \mathrm{p}$ - syndrome, such as round face, strabismus, carp mouth and pectus excavatum, are not observed in cases of rec(18) chromosome. Thus, distal $18 \mathrm{q}$ trisomy seems to be epistatic in its expression over 18p monosomy. Alternatively, the above signs of $18 \mathrm{p}$ - syndrome might be due to monosomy of the more proximal restricted segment of the short arm of chromosome 18 .

There have been a number of reported patients trisomic for only the distal region of $18 \mathrm{q}$ (18q21-qter), mostly derived from parental reciprocal translocation (Table 2), and these have been defined as the trisomy 18qter syndrome (Turleau and de Grouchy, 1977). As expected, their overall phenotypic spectrum is in some ways similar to that in the above 4 cases of chromosome rec(18) (Table 1).

Table 1 also presents the clinical pictures in full trisomy 18 syndrome, for comparison with those in the $4 \mathrm{rec}(18)$ cases and in cases of trisomy 18qter syndrome. In general, the features of patients with distal $18 \mathrm{q}$ trisomy, whether derived from

Table 2. Full karyotypes of reported cases showing partial trisomy for the 18q21-qter region, which are cited in Table 1.

\begin{tabular}{lcl}
\hline \multicolumn{1}{c}{ Karyotype } & $\begin{array}{c}\text { No. of } \\
\text { cases }\end{array}$ & \multicolumn{1}{c}{ Authors } \\
\hline $46, \mathrm{XX},-4,+\operatorname{der}(4) \mathrm{t}(4 ; 18)(\mathrm{q} 35 ; \mathrm{q} 21) \mathrm{pat}$ & 2 & Steele et al., 1974 \\
$46, \mathrm{XX},-14,+\operatorname{der}(14) \mathrm{t}(14 ; 18)(\mathrm{p} 13 ; \mathrm{q} 21.2) \mathrm{mat}$ & 1 & Turleau \& de Grouchy, 1977 \\
$46, \mathrm{XY},-21,+\operatorname{der}(21) \mathrm{t}(18 ; 21)(\mathrm{q} 21 ; \mathrm{q} 22) \mathrm{mat}$ & 1 & Niazi et al., 1978 \\
$46, \mathrm{XX},-9,+\operatorname{der}(9) \mathrm{t}(9 ; 18)(\mathrm{p} 24 ; \mathrm{q} 21) \mathrm{mat}$ & 1 & Fryns et al., 1979 \\
$46, \mathrm{XX},-6,+\operatorname{der}(6) \mathrm{t}(6 ; 18)(\mathrm{p} 24$ or p25;q21)pat & 1 & Fukuhara et al., 1979 \\
$46, \mathrm{XY},-4,+\operatorname{der}(4) \mathrm{t}(4 ; 18)(\mathrm{q} 35 ; \mathrm{q} 21.1) \mathrm{mat}$ & 1 & Matsuoka et al., 1981 \\
$46, \mathrm{XY},-9,+\operatorname{der}(9) \mathrm{t}(9 ; 18)(\mathrm{p} 24 ; \mathrm{q} 21) \mathrm{mat}$ & 1 & de Torres et al., 1984 \\
$46, \mathrm{XY},-7,+\operatorname{der}(7) \mathrm{rcp}(7 ; 18)(\mathrm{q} 36 ; \mathrm{q} 21) \mathrm{mat}$ & 1 & Borovik et al., 1987 \\
$46, \mathrm{XX},-9,+\operatorname{der}(9) \mathrm{t}(9: 18)(\mathrm{p} 22 ; \mathrm{q} 21.3) \mathrm{mat}$ & 2 & Tayel et al., 1988 \\
\hline
\end{tabular}


pericentric inversion or translocation, are clinically mild in comparison with those patients with full trisomy 18 syndrome. Several clinical signs, such as mental and growth retardation, auricular deformities and micrognathia, are seen commonly in both types of chromosome anomaly. However, some features characteristic of the full trisomy 18 are absent or very rare in cases of distal $18 \mathrm{q}$ trisomy. These include early death, microcephaly, congenital heart disease, urogenital malformation and abnormalities of the extremities.

The above findings imply that no critical region in the distal half of $18 \mathrm{q}$ is solely responsible for the typical phenotype of full trisomy 18 syndrome. Recently, in reviewing the phenotypes produced by various triplicated regions of chromosome 18 , Wilson et al. (1990) suggested that no single specific region of chromosome 18 would be sufficient to produce the phenotype of complete trimosy syndrome, and that some "interaction" between different chromosome regions might be necessary for the full manifestation of complete trisomy 18. This complex situation seems to be analogous to the phenotypic expression of full trisomy 13 syndrome (Schinzel et al., 1976), but in contrast to that of trisomy 21 (Down's) syndrome, which is due to trisomy of a well defined distal segment of 21q (Wahrman et al., 1976; Korenberg et al., 1990).

The general risk of producing recombinant offspring for carriers of pericentric inversion of chromosome 18 has been discussed in several articles (Vianna-Morgante et al., 1976; Vigi et al., 1977; Kukolich et al., 1978; Teyssier and Bajolle, 1980; Andrews et al., 1982). The probability of recombination would depend largely on the length of the inverted segment. In our present case, the length was about $60 \%$ of the total length of chromosome 18 . Since the mean number of chiasmata for chromosome 18 has been estimated to be 1.92 (ISCN, 1985), the number of chiasmata within the inverted segment concerned would be about 1.2. If one or three chiasmata were to occur within this region, recombinants would result (Fig. 3). Thus, it is predicted that a carrier mother would be at high risk of producing chromosomally unbalanced progeny, and this may have been partly responsible for the reproductive failures of our patient's mother, which included two abortions and one stillbirth.

Based on all the pericentric inversions reported in the literature, ascertained through affected children, Sutherland et al. (1976) suggested that the risk figures for recombinant formation by inversion carriers are $5 \%$ for males and $10 \%$ for females. With regard to inversions of chromosome 18 , the empirical risk has been estimated from the reported families to be 5-10\% (Vigi et al., 1977; Teyssier and Bajolle, 1980). Although the family data currently available are still limited, a more accurate estimate of the recombination risk is important in practice for genetic counselling, including prenatal diagnosis, in affected families.

Acknowledgment This work was supported in part by a Grant-in-Aid for Scientific Research from the Ministry of Education, Science and Culture of Japan, and by a Special Coordination Funds for Promotion of Science and Technology from the Science and Technology Agency, Japan. 


\section{REFERENCES}

Andrews, T., Gardiner, A.C. and Boon, A.R. 1982. Recombinant chromosome 18 in two offspring of a chromosome 18 inversion heterozygote. Ann. Génét. 25: 185-188.

Borovik, C.L., Brunoni, D., Sato, A.E., Stavále, J.N., Cardoso, S.H., Montezzo, L.C. and Perez, A.B.A. 1987. Holoprosencephaly as a result of unbalanced familial translocation $\operatorname{rcp}(7 ; 18)$ (q36;q21). Rev. Brazil. Genet. 10: 269-276.

De Grouchy, J. and Turleau, C. 1977. Clinical Atlas of Human Chromosomes. A Wiley Medical Publication, John Wiley \& Sons, New York, Chichester, Brisbane, Toronto, pp. 159-183.

De Torres, L., Ferrer, A.S. and Abrisqueta, J.A. 1984. Partial trisomy 18 due to a maternal translocation $\mathrm{t}(9 ; 18)$. Hum. Genet, $68: 272$.

Faust, J., Habedank, M. and Nieuwenhuijsen, C. 1976. The 18p- syndrome. Report of four cases. Eur. J. Pediatr. 123: 59-66.

Fryns, J.P., Van Der Hauwaert, L., Dumoulin, M. and Van Den Berghe, H. 1979. New chromosomal syndromes. II. Partial distal 18qter trisomy syndrome. Acta Paediatr, Belg. 32: 217219.

Fukuhara, K., Fukuhara, K., Mino, M., Kusunoki, T., Misawa, S., Morita, M. and Abe, T. 1979. Partial 18 trisomy syndrome resulting from paternal $6 / 18$ reciprocal translocation. Jpn. $J$. Human Genet. 24: 13-20.

Hodes, M.E., Cole, J., Palmer, C.G. and Reed, T. 1978. Clinical experience with trisomies 18 and 13. J. Med. Genet, 15: 48-60.

Ikeuchi, T. 1984. Inhibitory effect of ethidium bromide on mitotic chromosome condensation and its application to high-resolution chromosome banding. Cytogenet. Cell Genet. 38: 5661.

ISCN. 1985. An International System for Human Cytogenetic Nomenclature. Harnden, D.G. and Klinger, H.P., eds., Published in collaboration with Cytogenet. Cell Genet. (Karger, Basel, 1985).

Korenberg, J.R., Kawashima, H., Pulst, S., Ikeuchi, T., Ogasawara, N., Yamamoto, K., Schonberg, S.A., West, R., Allen, L., Magenis, E., Ikawa, K., Taniguchi, N. and Epstein, C.J. 1990. Molecular definition of a region of chromosome 21 that causes features of the Down syndrome phenotype. Am. J. Hum. Genet. 47: 236-246.

Jacobs, P.A., Melville, M., Ratcliffe, S., Keay, A.J. and Syme, J. 1974. A cytogenetic survey of 11,680 newborn infants. Ann. Hum. Genet., Lond. 37: 359-376.

Kukolich, M.K., Althaus, B.W., Sears, J.W., Mankinen, C.B. and Lewandowski, R.C. 1978. Abnormalities resulting from a familial pericentric inversion of chromosome 18. Clin. Genet. 14: 98-104.

Kunze, J., Stephan, E. and Tolksdorf, M. 1972. Ring-Chromosom 18. Ein 18p-/18q-Deletionssyndrom. Humangenetik 15: 289-318.

Matsuoka, R., Matsuyama, S., Yamamoto, Y., Kuroki, Y. and Matsui, I. 1981. Trisomy 18q. A case report and review of karyotype-phenotype correlations. Hum. Genet. 57: 78-82.

Niazi, M., Coleman, D.V. and Saldaña-Garcia, P. 1978. Partial trisomy 18 in a family with a translocation $(18 ; 21)(\mathrm{q} 21 ; \mathrm{q} 22) . \quad J$. Med. Genet. 15: 148-151.

Schinzel, A., Hayashi, K. and Schmid, W. 1976. Further delineation of the clinical picture of trisomy for the distal segment of chromosome 13. Report of three cases. Hum. Genet. 32: $1-12$.

Schinzel, A., Schmid, W., Luscher, U., Nater, M., Brook, C. and Steinmann, B. 1974. Structural aberrations of chromosome 18. I. The 18p- syndrome. Archiv. Genet. 47: 1-15.

Schinzel, A. 1984. Catalogue of Unbalanced Chromosome Aberrations in Man. Walter de Gruyter, 
Berlin, New York, pp. 604-668.

Shinohara, T., Ikeuchi, T., Asano, K., Hashimoto, K., Ueda, Y. and Ogoshi, T. 1985. A case of partial 18q trisomy resulting from a pericentric inversion of maternal chromosome 18. Jpn. J. Human Genet. 30: 160-161.

Steele, M.W., Pan, S., Mickell, J. and Senders, V. 1974. Trisomy for the distal half of the long arm of chromosome No. 18. J. Pediatr. 85: 827-829.

Sutherland, G.R., Gardiner, A.J. and Carter, R.F. 1976. Familial pericentric inversion of chromosome 19, inv(19)(p13q13) with a note on genetic counselling of pericentric inversion carriers. Clin. Genet. 10: $54-59$.

Tayel, S.M., Kurczynski, T.W., Casperson, S. and McCorquodale, M.M. 1988. Deletion 9p, duplication $18 \mathrm{q}$ in two sisters resulting from a maternal $(9 ; 18)(\mathrm{p} 22 ; \mathrm{q} 21.3)$ translocation. $\mathrm{Am}$. J. Med. Genet. 31 : 853-861.

Teyssier, J.R. and Bajolle, F. 1980. Duplication-deficiency of chromosome 18, resulting from recombination of a paternal pericentric inversion, with a note for genetic counselling. Hum. Genet. 53: 195-200.

Turleau, C. and de Grouchy, J. 1977. Trisomy 18qter and trisomy mapping of chromosome 18. Clin. Genet. 12: 361-371.

Vianna-Morgante, A.M., Nozaki, M.J., Ortega, C.C., Coates, V. and Yamamura, Y. 1976. Partial monosomy and partial trisomy 18 in two offspring of carrier of pericentric inversion of chromosome 18. J. Med. Genet. 13: 366-370.

Vigi, V., Maraschio, P., Bosi, G., Guerini, P. and Fraccaro, M. 1977. Risk for recombinants in pericentric inversions of the $(\mathrm{p} 11 \rightarrow \mathrm{q} 21)$ region of chromosome 18. Hum. Genet. 37: 1-5.

Wahrman, J., Goitein, R., Richler, C., Goldman, B., Akstein, E. and Chaki, R, 1976. The mongoloid phenotype in man is due to trisomy of the distal pale G-band of chromosome 21 . In Chromosomes Today, Vol. 5, Johns Wiley \& Sons, N.Y., Israel Universities Press, Jerusalem, pp. 241 248 .

Wilson, G.N., Heller, K.B., Elterman, R.D. and Schneider, N.R. 1990. Partial trisomy 18 with minimal anomalies: Lack of correspondence between phenotypic manifestations and triplicated loci along chromosome 18. Am. J. Med. Genet. 36: 506-510. 